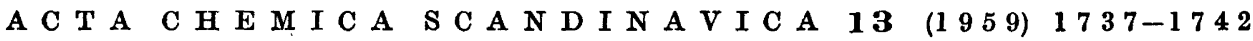

\title{
Electron Diffraction Conformational Analyses of Trans-1,4-Dichloro- and Dibromocyclohexane
}

\author{
V. A. ATKINSON and O. HASSEL
}

Universitetets Kjemiske Institutt, Blindern-Oslo, Norway

\begin{abstract}
Electron diffraction studies have been carried out on two trans-1,4dihalogencyclohexanes with chlorine and bromine as substituents. The results show that in the gas phase both compounds contain nearly equal amounts of the two possible conformations ( $a a$ and $e e)$. The energy difference between the two conformations must be less than $170 \mathrm{cal} / \mathrm{mole}$. Structural parameters of both conformations are given in Tables 1 and 2 for the dichloro and the dibromo compounds, respectively.
\end{abstract}

\begin{abstract}
$\mathrm{T}$ he fundamental principles of the stereochemistry of cyclohexane and its derivatives have been set out several years ago ${ }^{1}$. It is now generally accepted that the two inter-convertable forms of a particular cyclohexane derivative, both showing the "staircase" six-membered carbon ring, should in general possess different internal energies and therefore, according to statistical mechanics, be present in different concentrations in an equilibrium mixture. The energy difference will depend on the kind and number of substituents and on their positions in the molecule. The first attempt at a "conformational analysis" of a cyclohexane derivative was made in $1943^{2}$ and the substance investigated was monochloro-cyclohexane in the vapour state. The electron diffraction sector method was employed, but both the apparatus and the treatment of the experimental intensity curves used at that time were less satisfactory than those in use to-day in this laboratory. From differential radial distribution curves (i.e. the monochloroderivative minus cyclohexane itself) the conclusion was drawn that the number of molecules in the equilibrium mixture with chlorine in the equatorial positions considerably larger than the number of molecules with axial chlorine atoms. A quantitative measurement of the equilibrium constant was not attempted at that time. Some attempts have more recently been undertaken both in this laboratory and elsewhere, to determine more quantitatively the conformational equilibrium of cyclohexane derivatives using infrared spectroscopy or other experimental methods, but only in the liquid state or in the semi-liquid state of crystals containing "rotating" molecules ${ }^{3}$. The intermolecular forces can change the ratio of the con-
\end{abstract}

Acta Chem. Scand. 13 (1959) No. 9 
formations in condensed systems and we have therefore thought it worth while to try to determine equilibrium ratios in gaseous systems using modern electron diffraction technique. Considerable improvements have indeed been introduced since 1943 both in experimental technique and in the methods of treating the experimental data.

We have chosen trans-1,4-dichloro-cyclohexane and the corresponding dibromo compound for our experiments. X-Ray crystallographic investigations have shown that these two substances are both diequatorial in the solid state. Infrared absorption spectra seem to indicate, however, that both conformations are present in liquid systems ${ }^{4}$.

The measurements were carried out using the new Oslo electron diffraction apparatus ${ }^{5}$ with distances of 19 and $48 \mathrm{~cm}$ between the nozzle and the photographic plate. The intensity data extended from $s=1.25$ to $s=45$. The data were treated in the manner described in a series of papers from this institute published after 1955. The radial distribution curves thus obtained are shown in Figs. 1(a) and 2(a).

\section{RESULTS}

\section{Trans-1,4-dichlorocyclohexane}

The radial distribution curve shown in Fig. 1 (a) was obtained using a damping factor of 0.0015 . The full arrows show where the $\mathrm{C}(3)-\mathrm{Cl}, \mathrm{C}(4)-\mathrm{Cl}$ and $\mathrm{Cl}-\mathrm{Cl}$ distances of the ee form would be expected and the broken arrows show where the same distances of the $a a$ form would cause peaks. These distances are calculated on the basis of strictly tetrahedrally-directed carbon valences with bond distances: $\mathrm{C}-\mathrm{C}=1.53, \mathrm{C}-\mathrm{Cl}=1.81$ and $\mathrm{C}-\mathrm{H}=1.10 \AA$ obtained from the positions of the first three peaks. The $\mathrm{Cl}-\mathrm{Cl}$ peaks at 5.236 and 6.318 $\AA$ show that both conformations must be present in similar proportions.

Theoretical radial distribution curves were constructed from Gauss curves for both the ee and $a a$ conformations. It then became apparent that structures based on the strictly tetrahedral carbon atom would not give a composite theoretical radial distribution curve which would agree satisfactorily with the experimental curve. At this time parallel work in our department ${ }^{6}$ dealing with cyclohexane itself showed that the carbon ring in the parent hydrocarbon is more "flat" than would be expected if the $\mathrm{C}-\mathrm{C}-\mathrm{C}$ angle were strictly tetrahedral $\left(109^{\circ} 28^{\prime}\right)$. The value actually obtained from cyclohexane $\left(111.5^{\circ}\right)$, was used to calculate revised theoretical radial distribution curves for the two conformations of trans-1-4-dichlorocyclohexane.

In the case of the ee conformation the new curve appeared to agree with the experimental result, but a certain distortion of the $a a$ model was necessary in order to obtain a close agreement with the experimental curve. This distortion was a tilting of the $\mathrm{C}-\mathrm{Cl}$ bond away from the chief axis of the carbon ring. An angle of $6.3^{\circ}$ between the $\mathrm{C}-\mathrm{Cl}$ bonds and the axis turned out to give the best agreement with the experimentally observed maxima for which the aa conformation must be responsible. This tilting of the bonds of axial chlorine atoms agrees closely with earlier results from electron diffraction measurements of the cyclohexane derivatives ? 


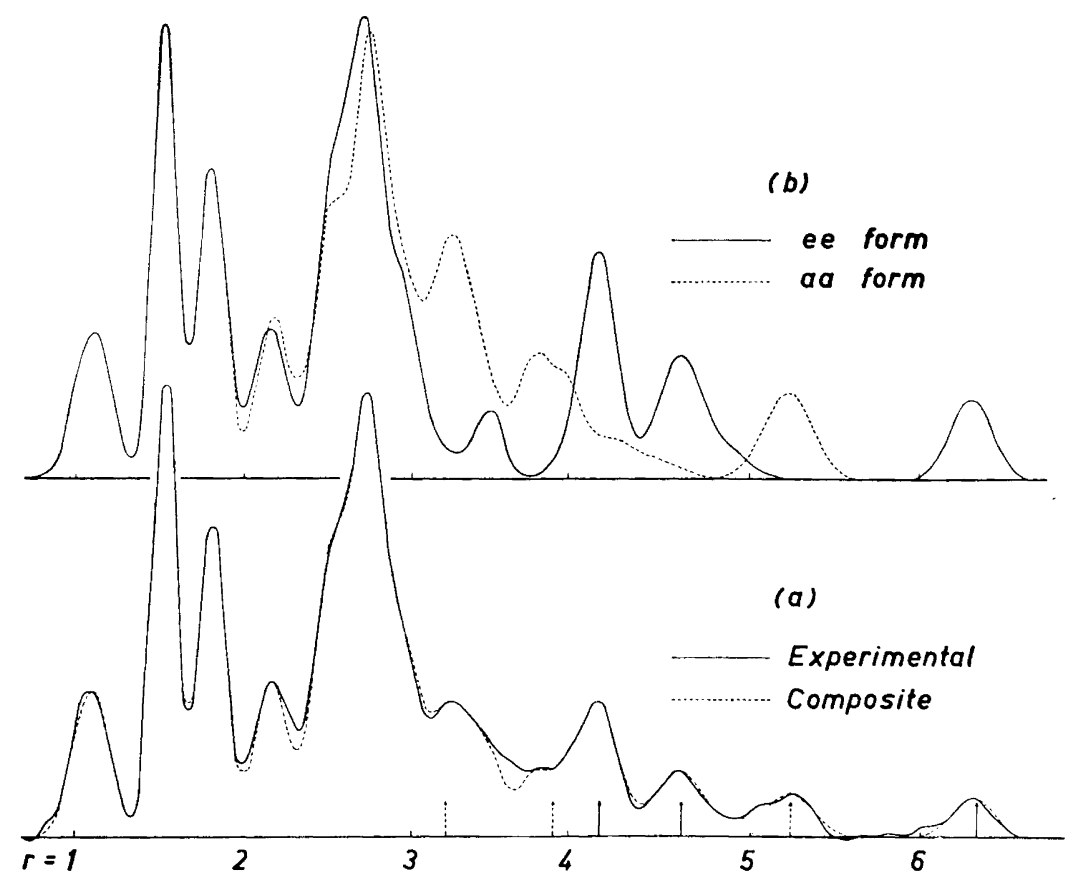

Fig. 1. Theoretical and experimental $\sigma(r) / r$ curves for trans-1,4-dichlorocyclohexane.

Fig. 1(b) shows the theoretical radial distribution curves for both conformations based on the structural parameters in Table 1.

Least squares computations lead to the conclusion that the composite theoretical radial distribution curve giving best agreement with the experimental curve should be constructed on the basis of $49 \%$ of the ee form and $51 \%$ of the $a a$ form. In Fig. 1(a) this composite radial distribution curve is compared with the experimental curve. The standard deviation is \pm 6 , i.e. $1.5 \%$ of the vertical scale used.

\section{Trans-1,4-dibromocycloh exane}

Fig. 2(a) shows the experimental radial distribution curve obtained for this compound using a damping factor of 0.0036 . The shape is similar to that of Fig. 1(a) showing that both conformations are again present in similar proportions.

The peak at $1.12 \AA$ due to the $\mathrm{C}-\mathrm{H}$ bond distance is lower than expected on theoretical grounds. This is probably due to some error in the selection of the experimental background to the intensity curve. However, this discrepancy, in a region where the $a a$ and $e e$ radial distribution curves are identical should not affect the conclusions, drawn from the other ends of the curves, about the proportions in which the two forms are present.

Acta Chem. Scand. 13 (1959) No. 9 


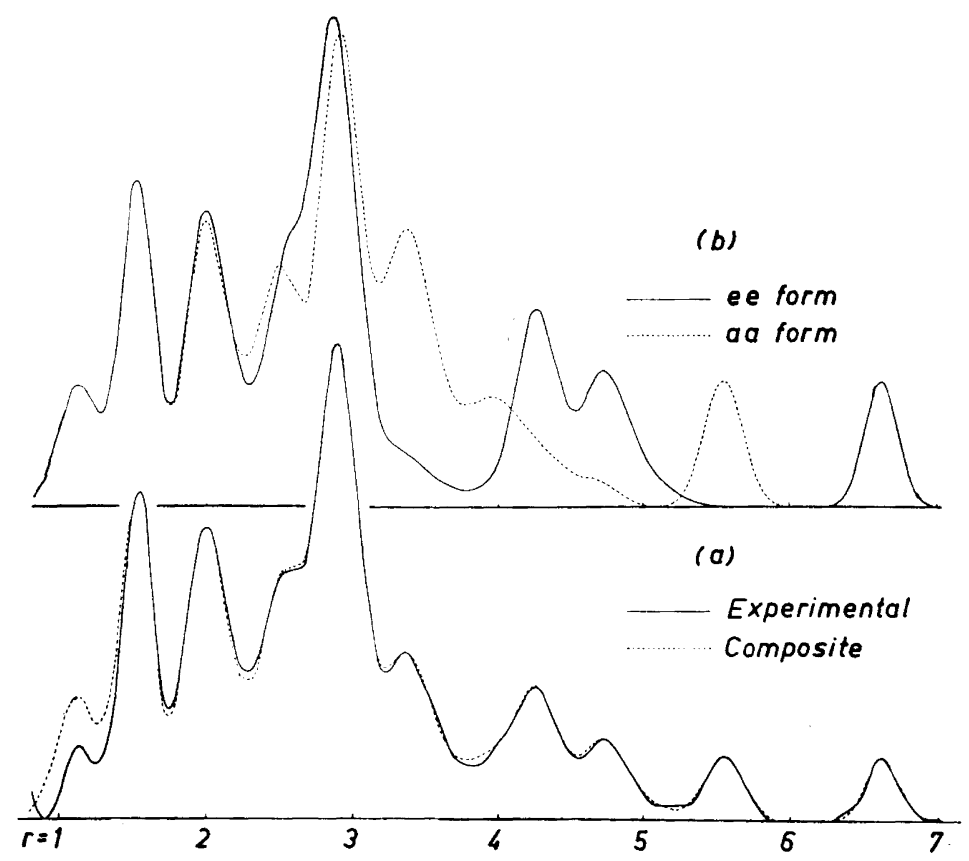

Fig. 2. Theoretical and experimental $\sigma(r) / r$ curves for trans-1,4-dibromocyclohexane.

Fig. 2(b) shows the theoretical radial distribution curves for the two conformations (ee and $a a$ ), based on the structural parameters given in Table 2. These parameters correspond to the same "flat" ring as was used for the chlorocompound. In the case of the aa form, there is again an extra distortion which tilts the bonds of the axial bromine atoms away from the main axis by an angle of $7.7^{\circ}$.

Least squares procedure showed that the composite radial distribution curve giving the best agreement with the experimental curve should have $51 \%$ $e e$ form and $49 \%$ aa form. In Fig. 2(a) this composite theoretical curve is compared with the experimental curve. The standard deviation for the latter part of the curve (where $r>1.5$ ) is \pm 4 .

\section{DISCUSSION}

The present conformational analyses clearly show that the amounts of the two forms present in the vapour state must be nearly equal. This result is contrary to that expected in the light of the old work on monochlorocyclohexane ${ }^{2}$.

The accuracy of the figures obtained clearly depends on the parameters chosen for the computation of the theoretical radial distribution curves for the $e e$ and $a a$ conformations. It appears very probable that small changes of the 
Table 1. Structural parameters used for trans-1,4-dichlorocyclohexane.

\begin{tabular}{|c|c|c|c|c|c|}
\hline \multicolumn{2}{|c|}{$\begin{array}{l}\text { Bond distances used } \\
\text { for both conformations }\end{array}$} & \multicolumn{2}{|c|}{$\begin{array}{l}\text { Bond } \\
\text { angles }\end{array}$} & $e e$ form & $a a$ form \\
\hline $\mathbf{C}-\mathbf{H}$ & $1.102 \AA$ & $\mathrm{C}-\mathrm{C}-\mathrm{C}$ & & $111.5^{\circ}$ & $111.5^{\circ}$ \\
\hline $\mathrm{C}-\mathrm{C}$ & $1.530 \AA$ & $\mathrm{C}-\mathrm{C}-\mathrm{Cl}$ & $=\mathrm{C}-\mathrm{C}-\mathrm{H}$ & $108.6^{\circ}$ & $110.6^{\circ}$ \\
\hline $\mathrm{C}-\mathrm{Cl}$ & $1.810 \AA$ & $\mathrm{H}-\mathrm{C}-\mathrm{Cl}$ & $=\mathrm{H}-\mathrm{C}-\mathrm{H}$ & $111.5^{\circ}$ & $107.6^{\circ}$ \\
\hline
\end{tabular}

Table 2. Structural parameters used for trans-1,4-dibromocyclohexane.

\begin{tabular}{|c|c|c|c|c|}
\hline \multicolumn{2}{|c|}{$\begin{array}{l}\text { Bond distances used } \\
\text { for both conformations }\end{array}$} & $\begin{array}{l}\text { Bond } \\
\text { angles }\end{array}$ & $e e$ form & $a a$ form \\
\hline $\mathrm{C}-\mathrm{H}$ & $1.12 \AA$ & $\mathrm{C}-\mathrm{C}-\mathrm{C}$ & $111.5^{\circ}$ & $111.5^{\circ}$ \\
\hline $\mathrm{C}-\mathrm{C}$ & $1.530 \AA$ & $\mathrm{C}-\mathrm{C}-\mathrm{Br}=\mathrm{C}-\mathrm{C}-\mathrm{H}$ & $108.6^{\circ}$ & $111.2^{\circ}$ \\
\hline $\mathrm{C}-\mathrm{Br}$ & $1.968 \AA$ & $\mathrm{H}-\mathrm{C}-\mathrm{Br}=\mathrm{H}-\mathrm{C}-\mathrm{H}$ & $111.5^{\circ}$ & $100.1^{\circ}$ \\
\hline
\end{tabular}

models would give slightly different theoretical radial distribution curves, which might have been combined in a slightly different proportion to give a composite curve which would have agreed equally well with the experimental curve. For this reason we assess our possible error in the ratio of the two conformations as high as $\pm 5 \%$. Even allowing for this error, the maximum energy difference between the two conformations obtained from Boltzmann's relation, is only $170 \mathrm{cal} / \mathrm{mole}$.

The structural parameters employed when calculating the radial distribution curves are based on identical bond lengths in the two interconvertible conformations. There appears to be no reason to expect a difference in bond distances which could be of any significance for the present investigation. The distances recorded are taken from individual peaks whose positions can be assessed with an accuracy of $\pm 0.5 \%$. The value of the $\mathrm{C}-\mathrm{H}$ bond distance for the bromine compound is associated with the major discrepancy between the theoretical and experimental curves and its error is estimated as $\pm 2 \%$.

The accuracy of the bond angles recorded in Tables 1 and 2 is more difficult to assess. The angles were chosen so that the theoretical and experimental radial distribution curves should show the best possible agreement. The influence of the bond distances involving hydrogen atoms on these curves is much less than that of the other distances. Therefore, only the $\mathrm{C}-\mathrm{C}-\mathrm{C}$, $\mathrm{C}-\mathrm{C}-\mathrm{Cl}$ and $\mathrm{C}-\mathrm{C}-\mathrm{Br}$ angles recorded have real significance for our problem. Their accuracy is put at $\pm 0.5 \%$.

In both compounds it was necessary to assume that the axial bonds to halogen atoms were tilted away from the chief axis of the ring. The value of $6.3^{\circ}$ for this deviation in the case of the dichloro compound agrees well with the $7^{\circ}$ deviation assessed for $1 a, 2 a, 4 e, 5 e$-tetrachlorocyclohexane ${ }^{7}$, and for "trans"-1,2-dichlorocyclohexane ${ }^{8}$.

This tilting is ascribed to steric hindrance between the axial halogen and the axial hydrogens attached to $\mathrm{C}(3)$ and $\mathrm{C}(5)$. It is significant that, in both

Acta Chem. Scand. 13 (1959) No. 9 
trans-1,4-dihalogeno-cyclohexanes, the effect of this deformation is to increase the $\mathrm{H}(3 a)-\mathrm{Hal}(a)$ and $\mathrm{H}(2 e)-\mathrm{Hal}(a)$ distances to approximately the same value. The actual distances were:!

$$
\begin{array}{ll}
\mathrm{H}(3 a)-\mathrm{Cl}(a)=2.88 \AA & \mathrm{H}(2 e)-\mathrm{Cl}(a)=2.86 \AA \\
\mathrm{H}(3 a)-\mathrm{Br}(a)=3.00 \AA & \mathrm{H}(2 e)-\mathrm{Br}(a)=3.05 \AA
\end{array}
$$

These are just within the limits expected from consideration of the van der Waal's radii $(\mathrm{H}=1.2 ; \mathrm{Cl}=1.8 ; \mathrm{Br}=1.95 \pm 0.1 \AA)^{9}$.

We wish to express our sincere gratitude to Mr. Arne Almenningen who was so kind as to take the electron diffraction pictures. We also wish to thank mag. scient. K. Lunde for letting us have pure samples of the compounds. Finally, thanks are due to Norges Teknisk-Naturvitenskapelige Forskningsråd for a postdoctorate fellowship (V.A.A.).

\section{REFERENCES}

1. Hassel, O. Quart. Rev. 7 (1953) 221.

2. Hassel, O. and Viervoll, H. Tidsskr. Kjemi, Bergvesen, Metallurgi 3 (1943) 35.

3. Yoshino, T. J. Chem. Phys. 23 (1955) 1974.

4. Lunde, K. Unpublished work.

5. Bastiansen, O., Hassel, O. and Risberg, E. Acta Chem. Scand. 9 (1955) 232.

6. Davis, M. Unpublished work.

7. Hassel, O. and Wang Lund, E. Acta Cryst. 2 (1949) 309.

8. Bastiansen, O., Hassel, O. and Munthe-Kaas, A. Acta Chem. Scand. 8 (1954) 872.

9. Pauling, L. The Nature of the Chemical Bond, Cornell University Press, N.Y. 1939.

Received July 6, 1959. 